\title{
GENERATIVITY AND GREEN PURCHASE BEHAVIOR: THE ROLE OF ENVIRONMENTAL CONCERN AND PRO-SOCIAL ATTITUDE Sajjad Ahmad Afridi ${ }^{*}$, Asad Shahjehan ${ }^{2}$, Maqsood Haider ${ }^{3}$, Sajida Gul ${ }^{4}$, Wajid Khan ${ }^{5}$ \\ ${ }^{1 *, 2}$ Assistant Professor, Department of Management Sciences, Hazara University Mansehra, Pakistan; ${ }^{3}$ Assistant Professor, Department of Management Sciences, FATA University, Pakistan; ${ }^{4}$ Assistant Professor, Department of Management Sciences Abasyn University Peshawar, Pakistan; ${ }^{5}$ Assistant Professor, Department of Management Sciences, University of Baltistan Skardu, Pakistan. \\ Emails: ${ }^{1 *}$ mrafridi79@gmail.com, ${ }^{2}$ asadshahjehan@hotmail.com, ${ }^{3}$ dr.haider@ fu.edu.pk, ${ }_{5}^{4}$ sajida.gul@abasyn.edu.pk, 5wajiduomm@gmail.com
}

Article History: Received on $17^{\text {th }}$ March 2021, Revised on $10^{\text {th }}$ April 2021, Published on $18^{\text {th }}$ April 2021

\section{Abstract}

Purpose of the study: This research intends to find out the role of generativity in green purchase behavior. Moreover, the mediating roles of environmental concern and pro-social attitude have also been proposed.

Methodology: This study was conducted on 689 university students given the sensitivity towards the concepts of generativity, environmental concern, pro-social attitude, and green purchase behavior. The model validity was verified by performing the exploratory factor analysis and confirmatory factor analysis. Finally, to test the hypotheses, hierarchal regression was performed.

Main Findings: Results endorsed the positive impact of generativity concern on green purchase behavior. Additionally, the mediating roles of Environmental concern and pro-social attitude were also verified.

Applications of this study: This study will be very useful for companies that are offering green products/services.

Novelty/Originality of this study: This study distinguishes itself from prior studies by adding new predictors to the model of green purchase behavior. Furthermore, this study verifies the role of Environmental concern and Pro-social attitude on the link of GEN-GPB.

Keywords: Sustainability, Generativity, Environmental Concern, Pro-social Attitude, Environmental Behavior.

\section{INTRODUCTION}

The consumption of products and services has risen considerably in the world during the past decades, contributing to the loss of natural resources and severe environmental disruption (Chen \& Chai, 2010). As climate change has become a vital subject for individuals, businesses, and cultures, environmental degradation, globalization, exploitation of natural capital, and industrialization are the major concerns and problems confronting any citizen on earth (Yew, Lim, \& Lee, 2019). To overcome this challenge, numerous studies have attempted to examine consumers' attitudes towards green products and services (Groening, Sarkis, \& Zhu, 2018; Shiel, do Paco, \& Alves, 2020). Human actions are creating severe environmental issues (IPCC, 2014) and households are a major contributor to-them (Pothitou, Hanna, \& Chalvatzis, 2016). In this scenario, consumer green purchase behavior (GPB) is critical (Steg \& Vlek, 2009; Wang, Wong, \& Alagas, 2020) and companies should look into what causes consumers to buy green products and services (Hsu, 2016; Keho, 2016). While people are more conscious than ever before of climate change and environmental concerns (IPCC, 2014), the share of individuals who are personally committed to the environment remains very limited (Cleveland, Kalamas, \& Laroche, 2012). GPB is important because unplanned purchases of products and services may significantly affect the environment (Joshi \& Rahman, 2015). GPB is an eco-friendly way of buying and using goods and services (

Nevertheless, previous studies have shown that consumers are more positive about the environment (Han, 2020; Witek \& Kuźniar, 2021), however, no evidence shows that the demand for green products and services has increased. Despite the favorable attitude of consumers towards the environment, the environmental-friendly product share is still reported 1 to $3 \%$ of the whole market (Bray, Johns, \& Kilburn, 2011). It implies that a favorable attitude towards the environment alone may not be enough to encourage GPB. Notwithstanding extensive research, studies often get contradictory findings on consumer's intentions and actions. It is yet unclear, that why consumers with a positive attitude toward environmentally friendly products and services act differently while purchasing the product and services (Biswas, 2017). Furthermore, environmental attitudes were not specifically studied in the past and the associations between green attitudes, beliefs, and actions are still not clear. It, therefore, goes without saying that previous studies have been inconclusive in getting the answer of; why a positive consumer attitude about the environment does not result in GPB (Gupta \& Ogden, 2009). Such a situation is referred to "attitude-behavior gap" (Alwitt \& Pitts, 1996) that has recently been explained in several ways. For instance, Ajzen and Fishbein (1980) argued that it is because of the measurement issues. When measured at the same abstraction level, 
the relationship between attitudes and behavioral structures is greater. Because attitudes like environmental issues are more common than specific contextualized activities, their statistical association could be poor (Fransson \& Gärling, 1999).

Another reason might be that the environmental behavior model does not contain all relevant variables. Due to the interaction intricacy of the behavioral dimensions and behavior itself, it is not easy to add all related variables to a common model. For instance, self-interest is supposed to drive the process in most consumer behavior models, but for the environmental-related behaviors (ERBs) this is not the case, since the behavior does not benefit directly from it. This altruistic tendency has demonstrated an impact on environmental concern, intentions, and behavior (Schultz, 2001). Additionally, social structure variable such as race (Farrow, Grolleau, \& Ibanez, 2017; Johnson, Bowker, \& Cordell, 2004), gender (Sreen, Purbey, \& Sadarangani, 2018; Vicente-Molina, Fernández-Sainz, \& Izagirre-Olaizola, 2018), demographic (Dietz, Stern, \& Guagnano, 1998; Hansmann, Laurenti, Mehdi, \& Binder, 2020), and geography (Carrus, Bonaiuto, \& Bonnes, 2005; Ifegbesan \& Rampedi, 2018) have also been examined as the attributes of environmentally friendly behavior. Furthermore, a series of psychological factors have been supported empirically, indicating their relationship with the environment, green attitudes, and behaviors. For instance, Prakash et al. (2019) studied the impact of altruism on ecofriendly actions, and conclude that willingness to engage in political action in an environmental sense is influenced by altruism and egoism. Besides, the positive impact of perceived consumer effectiveness on eco-friendly consumer behavior has been endorsed by many scholars (see for example Achchuthan \& Thirunavukkarasu, 2016; Jaiswal \& Kant, 2018; Zhao, Gao, Wu, Wang, \& Zhu, 2014). Such findings suggest that customers will respond correctly if they know that their decisions would affect. Several researchers have also examined value orientation and their relation to environmental concerns and environmentally friendly behavior and found that they are positively associated with concerns and behavior (Ahmad, Kim, Anwer, \& Zhuang, 2020; Buerke, Straatmann, Lin-Hi, \& Müller, 2017; Han, Hwang, \& Lee, 2017).

The psychological variables associated with environmentally friendly behavior, as can be seen, are wide in scope, and in the past 30 years, these variables have been studied for some time. Yet those examined do not exhaust the spectrum of alternatives, and several others may also be claimed that they are related. Whether and how individuals view the world relies on a variety of psychological factors which can exist at any moment. Some of these states are temporary and may vary under different conditions while some will last longer. Those with a lasting impact are of keen interest due to its role in the decline or rehabilitation of the environment has long-term effects on themselves as well as future generations. This poses the question of intergenerational justice which is largely neglected in the field of marketing and business-related discipline. Generativity (GEN) is considered as a psychological variable that expresses one's future orientation (Erikson, 1950). It is worth examining to further study its role in GPB in some depth because of its relation to intergenerational justice. Since one of the features that the present generation wants to move forward with is the condition of the environment, GEN role in such an aspect is very crucial to examine. Furthermore, a significant aspect of ensuring an ecological future would be reducing the manufacturing and use of goods that harm the environment while encouraging eco-friendly products/services (Liobikiené \& Bernatoniene, 2017). Individuals with high levels of generative concern remain highly involved in cohesiveness, restoration of ecological systems, and the safety of future generations (Aubin \& McAdams, 1995; Shiel et al., 2020). In most of the studies, building a greener environment is implicit, but the degree to which consideration for the environment influences customer decisions is not explicitly considered. Provided that GEN increases the value of work on the potential effects of current actions on the future, it is well worth examining its role in consumer GPB.

Another psychological variable that might play an effective role in closing the attitude-behavior gap and motivate proenvironmental behavior may be an environmental concern (EC) (Gifford, 2008; Kulin \& Johansson Sevä, 2020). Since GEN implies feelings of responsibility and future generation concern, it might play a significant role in inspiring EC. Moreover, the model of GEN by McAdams and Aubin (1992) proposes that EC may be addressed with generative concern and generative action. Considerations of the Earth's ability to sustain future generations may now lead to an environmentally friendly decision (Moore \& Nelson, 2010) and offer a framework to amplify GEN in this field. Plentiful qualitative research is available to support the positive association of GEN and EC (Barnett, Archuleta, \& Cantu, 2019; Chan, 2009; Guiney \& Oberhauser, 2009; Kulin \& Johansson Sevä, 2020). It is evident from these qualitative studies that generative concern is an important motivation for environmental concern. Besides qualitative research, the argument got significant support in quantitative research as well (for example Milfont \& Sibley, 2011; Shiel et al., 2020; Urien \& Kilbourne, 2011).

Consequently, the concern for the environment refers to an individual's overall environmental interest which is found to be an important indicator of environmentally conscious behavior that ranges from recycling activity (Kropfeld, Nepomuceno, \& Dantas, 2018; Ramayah \& Rahbar, 2013; Wu, Liao, Wang, \& Chen, 2019) to eco-consumerism (Bertrandias \& ElgaaiedGambier, 2014; Chaudhary \& Bisai, 2018). For instance, individuals who possess stronger values for EC are more likely to purchase environmentally friendly products (Cerri, Testa, \& Rizzi, 2018) than those individuals who are less concerned for the environment. Considerable empirical evidence is available that endorse the argument that individuals with a stronger environmental concern are more inclined towards Eco-consumerism (Cerri et al., 2018; Heo \& Muralidharan, 2019; Malik et 
al., 2019; Song, Qin, \& Yuan, 2019). Thus, it is believed that individual who scores high on generativity may likely possess high EC and may likely engage in GPB.

Besides EC, the concern for society with prosocial motives is another important psychological element to investigate. Since Consumer behavior does not occur in a vacuum, it is therefore important to examine how individual concerns for future generations affect the social factors that affect behavior and the association between social and green behavior. In the theory of psychosocial development, Erikson proposes that individual and their social life are concomitant for each other. It further posits that the concept of generativity is not limited to ego-centric motivation, but rather a dynamic attribute of psychological development in which ego-centric and social-centric attributes co-exist and interact. This argument is also endorsed by Marcia (2010) by stating that generativity ranges from self-centered to being society-centered and the attitude towards society is an integral part of generativity. Furthermore, the generative individual is argued to be more politically conscious and expected to support movements that are in favor of social justice and would be more attached to the society and civic agency (Serrat, Villar, Warburton, \& Petriwskyj, 2017; Timilsina, Kotani, \& Kamijo, 2019). Similarly, Morselli and Passini (2015) endorsed the positive association of generativity and prosocial attitudes. Thus, in the social context, the concept of generativity should be concerned with how individuals engage his/her self in family and friends relationships, their vicinities, social activities, and social institutions. Although nearly any social attitude is over-determined by several forces and factors, we believe that GEN would be the significant force that encourages pro-social attitude such as; "providing social support, volunteerism and civic activities".

Furthermore, Thielmann, Spadaro, and Balliet (2020), propose that pro-social behavior includes supporting others and acts directed at preserving or enhancing others' well-being. Since, GPB is a complex form of the ethical decision-making process of buying products and services that are deemed environmentally friendly (Chan, 2009), and a form of socially responsible behavior in which green consumers consider the impact of their consumption on the public, bringing about social change within their purchasing power (Moisander, 2007), and restricting unplanned consumptions of products which may affect the environment (Joshi \& Rahman, 2015). We believe that individuals that consider the well-being of others and society would tend to be more inclined towards green purchase behavior. Furthermore, prosocial attitudes are about interpersonal relationships, they do represent the attitudes of individuals towards society and others thus could be a significant element in integrating green practices into every model.

Previously, the model of green consumer behavior has been theorized and examined with the help of the "Theory of Reasoned Action" (TRA) and "Theory of Planned Behavior" (TPB) to evaluate individual attitudes and behaviors. The TRA focuses on the behavior intention whereas TPB added Perceived Behavioral Control to predict consumer GPB (Paul, Modi, \& Patel, 2016). Despite such theoretical models, developing an ideal and consensual model that predicts consumer GPB is still questionable. As a whole, previous researches suggest that there is a gap between consumers' environmental attitude and actual eco-friendly behavior and recommend that there is a need to examine various factors influencing consumer green purchase behavior (Biswas, 2017; He, Cai, Deng, \& Li, 2016).

Hence responding to the call for further research in the domain of GPB, the present study aims to contribute by examining the role of generativity, environmental concerns, and pro-social attitude in predicting GPB.

\section{LITERATURE REVIEW}

\section{Generativity and Green Purchase Behavior}

The idea of GEN was first proposed by Erikson (1950) which comprised the concern for instituting and guiding future generations. GEN, thus defined by Kotre $(1984$, p. 10) as "a desire to invest one's substance in the form of life and work that will outlive the self". Kotre expressed generativity, like the desire to live in a way that has effects beyond the life span of the individual. Likewise, Urien and Kilbourne (2011) described generativity as "a resource encouraging people toward the public good, maintaining continuity from one generation to the next" (p.73). More comprehensively, McAdams and Aubin (1992) come up with seven interlinked attributes of generativity: "cultural demand", "inner desire", "generative concern", "belief in the species", "commitment, generative action", and "person narration". The present study focuses on one aspect of the seven attributes presented above; i.e, generative concern. The generative concern is referred to as a general personality predisposition with conscious concerns for the well-being of others. More precisely, generative concern is the degree to which an individual articulates a persistent concern or obsession with a meaningful and enduring effect on the future generation. Individuals with high levels of generative concern remain highly involved in cohesiveness, restoration of ecological systems, and the welfare of future generations (Aubin \& McAdams, 1995).

Consequently, the concept of GPB applies to the purchase of products and services that are environment-friendly (Chan, 2009). GPB is a complex form of the ethical decision-making process of buying products and services that are deemed environmentally friendly (Chan, 2009), and a form of socially responsible behavior in which green consumers consider the impact of their consumption on the public, bringing about social change within their purchasing power (Moisander, 2007), 
and restricting unplanned consumptions of products which may affect the environment (Joshi \& Rahman, 2015). Thus, a significant aspect of ensuring an ecological future would be reducing the manufacturing and use of goods that harm the environment while encouraging eco-friendly products/services (Liobikiené \& Bernatoniené, 2017). Since a noteworthy percentage of consumer purchases are responsible for environmental damage (Grunert, 1995) with a harmful impact on future generations, consumers with their GPB can play a significant role in preventing or reducing the harm to the environment. Despite consumers' positive attitude towards the greener environment (Jaiswal \& Kant, 2018) and demand for green products (Bockman, Razzouk, \& Sirotnik, 2009; Shiel et al., 2020), limited research is conducted that shows the increase in the purchase of the environmentally friendly product. While one thing that the current generation will pass on to the future generation is the state of the environment, the concept of generativity is therefore very important in models of GPB.

Despite, the importance of GEN in individual GPB, this link has been seldom examined. Previously, GEN has been examined with social involvement (Hart, McAdams, Hirsch, \& Bauer, 2001) volunteering (de Espanés, Villar, Urrutia, \& Serrat, 2015; Son \& Wilson, 2011), social motives (Peterson \& Stewart, 1993), and personality (Peterson, Smirles, \& Wentworth, 1997). Additionally, the importance of generativity in pro-environmental behavior such as; environmental commitment (Chan, 2009), environmental engagement and attitude, environmental activism (Alisat, Norris, Pratt, Matsuba, \& McAdams, 2014), and in generativity concern to conservation volunteers (Guiney \& Oberhauser, 2009) have been studied. More recently, it is linked with consumer behavior (e.g, Lacroix \& Jolibert, 2015; Shiel et al., 2020; Urien \& Kilbourne, 2008; Urien \& Kilbourne, 2011). Besides, Urien and Kilbourne (2011) report that individuals with a high score on generativity indulge more in environmentally friendly purchasing behavior when self-enhancement is high. This suggests that people who think their potential contributions are important are more likely to be green buyers. As discussed earlier, individuals with a high degree of generative concern continue to play a meaningful role in the cohesion, reconstruction, and protection of future generations (Aubin \& McAdams, 1995). In most research, it is not clear to create a greener atmosphere nor to what extent consumer choices are influenced by concern for the environment. GEN is worth exploring its position in the consumer GPB, given that GEN increases the importance of working on the possible impact of current action on the future. We believe, that individual who posses high values for GEN would likely be more engage in GPB. Henceforth, the first hypothesis of the study is formulated;

$\mathbf{H}_{\mathbf{1}}$ : Generativity is positively and significantly associated with consumers' green purchasing behavior.

\section{The Intervening Role of Environmental Concern}

Nevertheless, the concept of GEN and consumer GPB has been studied extensively in the past (e.g, Shiel et al., 2020; Urien \& Kilbourne, 2008; Urien \& Kilbourne, 2011). However, the underlying mechanism between the link of GEN and consumer GPB is still not clear. One of the primary objectives of this research is to verify the intervening role of EC between the link of generativity and consumer GPB. EC is expressed as, "the degree to which people are aware of environmental problems and support efforts to solve them and/or indicate a willingness to contribute personally to their solution (Dunlap \& Jones, 2002, p. 484)". Though empirical evidence that links generativity with environmental concern is limited, scholars have attributed generativity as an important contributor in EC (e.g, Horwitz, 1996; Urien \& Kilbourne, 2011) and generative concern has repeatedly been quoted as a motive in the ethical and moral literature on environmental calamity (Moore \& Nelson, 2010). Besides, Pratt, Norris, Alisat, and Bisson (2013) observed the impact of GEN on EC in adolescent and their parents and reported a positive and significant impact of GEN on EC. More recently, Barnett et al. (2019) examined the role of generativity between political conservatism and environmental attitudes. Their findings revealed that the concern for future generations plays a positive and significant role between politically conservative individuals and pro-environmental attitudes. Their findings conclude that individuals who are more politically conservative tend to be more concerned towards future generations and will exhibit more pro-environmental attitudes.

GPB has a significant role in the prevention or reducing the harmful effect on the environment. For example, Chen and Chang (2013) argued that consumers formed a strong inclination towards environmentally sustainable goods in consideration of EC. Similarly, Hartmann and Apaolaza-Ibáñez (2012) report that consumer EC has raised their intention to buy green products. More recently, Testa, Iraldo, Vaccari, and Ferrari (2015) report a strong correlation between health promotion and environmental concerns that ultimately promote buying of green products. Furthermore, Polonsky, Vocino, Grimmer, and Miles (2014) conclude that individual with pro-environmental belief has a positive impact on consumer GPB. Literature concerning consumer behavior also acknowledged the positive impact of consumers' environmental concern with consumer' willingness to pay (Bang, Ellinger, Hadjimarcou, \& Traichal, 2000), environmentally friendly behavior (Abeliotis, Koniari, \& Sardianou, 2010), and purchase of ecologically friendly products (Alwitt \& Berger, 1993; Kalafatis, Pollard, East, \& Tsogas, 1999). Besides, Bang et al. (2000) reported that consumers who are high on EC are willing to pay more to get renewable energy. Likewise, Abeliotis et al. (2010) found that out of $80 \%$ of the consumers in their study showed a higher concern for the environment while only $20 \%$ were willing to change their buying behavior for such cause. In another study, Kim and Choi (2005) documented a strong and positive impact of EC on consumer GPB. 
More importantly, the mediating role of EC has also been acknowledged by Huang and Liu (2017) and Zhang, Wang, and Lai (2015). Huang and Liu (2017) tested the mediating and moderating role of EC and ecotourism experience between the relationship of motivation and revisit intention and confirmed that EC mediates and moderates the said association. Furthermore, Zhang et al. (2015) investigated the mediating role of managers' EC between external factors and organizational energy-saving practices and found that managers' EC has a significant effect on this relationship. Besides the positive role of EC in GPB, there are some contradictory findings concerning the impact of EC on GPB. For example, Malik et al. (2019) examined the mediating effect of EC between green purchase awareness and GPB. They collected data from fast food consumers and revealed that EC has no role in mediating the association of green purchase awareness and GPB.

EC as a mediator has not been explored extensively, there are only a few studies that have examined the mediating effect of EC (see e.g, Huang \& Liu, 2017; Malik et al., 2019; Zhang et al., 2015) with contradictory results. This shows that the role of EC in GPB is still questionable and needs to be explored further (Malik et al., 2019). Responding to the call, the present study will examine the mediating effect of EC between the link of GEN and GPB. Because we believe that those individuals who are more generative will likely be more participative in environmental issues and will demonstrate and support ECs. Since the EC is the evaluation of one's behavior, or attitude towards fact, or others behavior with the concerns for environment (Weigel, 1983) it can be proposed that individuals with greater environmental concerns will likely enhance their intentions to buy green product or services. Thus, the second hypothesis of the study is formulated;

H2: Environmental concern positively and significantly mediates the association between generativity and consumer green purchase behavior.

\section{Mediating Role of Pro-social Attitude}

The principle of GEN has found new applications in recent years, especially in empirical studies in the fields of personality psychology, sociology, and the life course (e.g, Aubin, McAdams, \& Kim, 2004; Kotre, 1984; McAdams \& Aubin, 1992). Erikson in his theory of psychosocial development presents a key virtue that is the relation between psychological growth and social contexts of the individual to understand their psychological growth. Therefore, based on the theoretical framework of Erikson, the concept of generativity is not limited to self-centered, but the combination of self and societal centered. Furthermore, Peterson and Stewart (1996) and Water and McAdams (1989) concluded that a generative individual is more politically conscious and expected to support movements that are in favor of social justice. More recently, the study of "Midlife Development in the United States" (MIDUS) reported that GEN is the most reliable indicator of several attributes of social responsibility, for example, voluntary work and contributing time and money for the social concern. Additionally, Cole and Stewart (1996) reported that individuals high on generativity tend to be more attached to society. In another study, Morselli and Passini (2015) found a significant impact of generativity on prosocial attitudes. Moreover, Hart et al. (2001) examine the link of generativity with social involvement and found that generativity positively influences social involvement and generative parents were emphasizing prosocial values. Thus, in the social context, the concept of generativity should be concerned with how individuals engage his/her self in family and friends relationships, their vicinities, social activities, and social institutions. Although nearly any social attitude is over-determined by a number of forces and factors, we expect that generative concern would be the significant force that encourages pro-social attitude such as; providing social support, volunteerism and civic activities.

Nevertheless, a prosocial attitude is referred to as an individual's persistent dispositional tendency to feel and think about the well-being and rights of others, and to be empathetic (Weinstein \& Ryan, 2010). While prosocial attitudes are about interpersonal relationships, they do represent the attitudes of individuals towards society and others, this could be a significant element in integrating green practices into every model. In this regard, Zabkar and Hosta (2013) empirically confirmed that eco-friendly consumption increases with the increase of social status. More precisely, the authors say that the prosocial status of green consumer behavior reduces the gap between the predisposition to act in an eco-friendly way and truly behaving in an effective eco-friendly way. Besides, Welte and Anastasio (2010) argue that social context can limit, endorse, or even disrupt individual goal-seeking behavior by imposing certain rules and values to convince individuals to behave in a certain way. Authors further suggest that social contexts and beliefs on how people view such behavior are essential indicators of eco-friendly behavior such as green consumption. Further, Steele et al. (2008) argue that individuals with stronger prosocial behavior, often appear to possess a pro-social personality marked by the ability to practice altruistic behaviors (eco-friendly). Furthermore, do Paco, Shiel, and Alves (2019) found a positive effect of prosocial attitude on green consumption values which further leads to consumer buying behavior. Thus, based on the aforementioned empirical discussion, we believe that individuals high on generativity are likely to have a stronger prosocial attitude that leads to individual green consumption behavior. Hence, the third hypothesis of the study is formulated.

H3: Prosocial attitude significantly mediates the association between generativity and green purchase behavior. 


\section{Conceptual Framework}

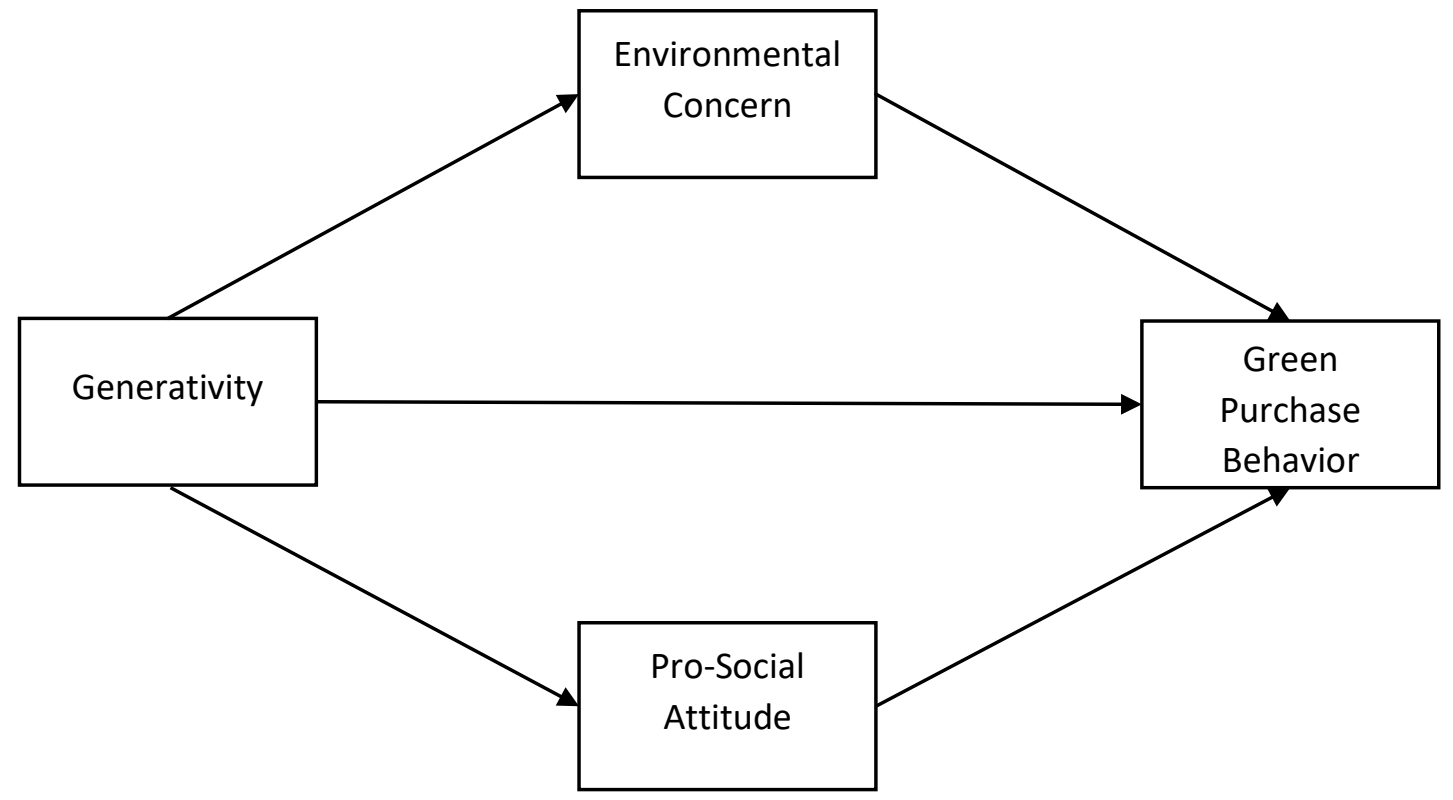

Figure 1: Conceptual Framework

\section{METHODS}

This study was conducted on students from a university in the North West, Pakistan. For this study, young students of a university were chosen because according to the literature review of study variables, young adults are more sensitive to the concepts of generativity, environmental concern, pro-social attitude, and green purchase behavior. Convenience sampling was used. Two research assistants were hired and they collected data from students of various departments. One research assistant approached students from social sciences major and the other research assistant was asked to collect data from all remaining departments. The purpose of the study was shared with students and those who showed consent were given surveys. In total, 1100 surveys were distributed. The final sample was 689 students. Among the sample $476(68 \%)$ were male and $222(32 \%)$ were female. Furthermore, $304(44 \%)$ were undergraduate while $385(56 \%)$ were postgraduate students. The mean age of the sample was 23.10 years with a standard deviation of 2.68 years. The students in the final sample were from various departments such as business education, arts, law, psychology, botany, microbiology, physics, chemistry, computer sciences, and agricultural sciences.

\section{Measures}

\section{Generativity}

The generative Concern scale was adopted from McAdams and Aubin (1992) consisting of 16-items including "I feel as though my contribution will exist after I die" and "I think that I will be remembered for a long time after I die". The Cronbach alpha reported for the study is 0.818 .

\section{Pro-social attitude}

The pro-social attitude scale developed by Osgood and Muraven (2015) was used to assess pro-social attitude. The instrument comprises of 6-items including "the well-being of others is important". This scale is used because it might address the difference between intention and green behavior (Zabkar \& Hosta, 2013). The reliability reported is 0.805 .

\section{Environmental concern}

It was measured with the help of a 15-item scale proposed by (Dunlap, Van Liere, Mertig, \& Jones, 2000). The sample items include; "plants and animals have as much right as humans to exist" and "if things continue on their present course, we will soon experience a major ecological catastrophe". The Cronbach alpha reported for the study is 0.748 .

\section{Green purchasing behavior}

A 10-items scale was adapted to measure GPB developed by (Paço, Alves, Shiel, \& Filho, 2013). The sample items include; "I try to buy energy-efficient products and appliances" and "I have switched product/brands for an ecological reason". The Cronbach alpha reported for the study is 0.87 . 
The respondents assessed these scales on a seven-point, Likert scale "ranging from $1=$ strongly disagree to $7=$ 'strongly agree".

\section{RESULTS}

The model validity was verified by performing the exploratory factor analysis (EFA) and confirmatory factor analysis (CFA). EFA evaluated the factor structure of study variables (generativity, environmental concern, pro-social attitude, and green purchase behavior) and results show that all the items significantly load on their respective factor and the factor loadings were above 0.5 and no cross-loading difference was greater than 0.4. To assess the discriminate and convergent validity of the variables, CFA was utilized. The results are presented in Table 1.

Table 1: Model Validity

\begin{tabular}{llllllll}
\hline Model & $\boldsymbol{\chi} \mathbf{2}$ & $\mathbf{d f}$ & $\boldsymbol{\chi} \mathbf{2} / \mathbf{d f}$ & GFI & CFI & NFI & RMSEA \\
\hline 1 & 2678.42 & 281 & 9.53 & 0.520 & 0.617 & 0.597 & 0.156 \\
\hline 2 & 1641.37 & 304 & 5.40 & 0.684 & 0.781 & 0.752 & 0.112 \\
\hline 3 & 1352.43 & 302 & 4.48 & 0.749 & 0.823 & 0.793 & 0.099 \\
\hline 4 & 465.98 & 233 & 2.00 & 0.923 & 0.938 & 0.909 & 0.053 \\
\hline One factor solution & All study variables & & & \\
\hline Two-factor solution & Factor 1: Generativity \& Environmental Concern \\
& Factor 2: Pro-social Attitude \& Green Purchase Behavior \\
\hline Three-factor solution & Factor 1: Generativity \\
& Factor 2: Environmental Concern \\
& Factor 3: Pro-social Attitude \& Green Purchase Behavior \\
\hline Four-factor solution & Factor 1: Generativity \\
& Factor 2: Environmental Concern \\
& Factor 3: Pro-social Attitude \\
& Factor 4: Green Purchase Behavior & \\
&
\end{tabular}

From Table 1, it can be observed that the four-factor solution is the best fit for the data $(\chi 2 / \mathrm{df}=2.00$, GFI $=0.923$, CFI $=$ 0.938, NFI $=0.909$, RMSE $=0.053$ ). The alternate models do not provide a better fit than the four-factor model. The correlation and corrected correlations of the study variables are shown in Table 2. A difference was found between the observed and true correlation of the study variables, however, the observed correlations always underestimate the true correlation (Salgado, Blanco, \& Moscoso, 2019). This very issue is addressed in Table 2. A formula was used to correct the observed correlation for attenuation to assess the measuring error in X and Y (see e.g, Schmidt, 2015). Because this formulation involves the reliability coefficients of the study variables, these have been derived from the calculated internal consistency of generativity, environmental concern, pro-social attitude, and green purchase behavior.

Table 2: Correlation Corrected Correlations

\begin{tabular}{llllllll}
\hline & AGE & GEN & PROG & Generativity & EC & PSB & GPB \\
\hline GEN & -0.088 & & & & & & \\
\hline PROG & $0.181^{* *}$ & $0.105^{*}$ & & & & & \\
\hline Generativity & 0 & -0.067 & -0.053 & $(0.818)$ & & & \\
\hline EC & 0.075 & $-0.128^{* *}$ & -0.009 & $0.290^{* *}$ & $(0.748)$ & & \\
\hline PSA & 0.066 & -0.066 & 0.005 & $0.352^{* *}$ & $0.256^{* *}$ & $(0.805)$ & \\
\hline GPB & 0.089 & -0.012 & 0.038 & $0.352^{* *}$ & $0.226^{* *}$ & $0.298^{* *}$ & $(0.87)$ \\
\hline Corrected correlations for GPB & & 0.436 & 0.270 & 0.353 & \\
\hline$* 0.05, * * 0.01$ significance level & & & & & \\
(Cronbach Alpha) & & & & & & \\
\hline
\end{tabular}

Table 2 shows that GPB has a positive and significant correlation with generativity $(\mathrm{R}=0.352, \mathrm{p}<0.01), \mathrm{EC}(\mathrm{R}=0.226$, $\mathrm{p}<0.01)$, and PSA $(\mathrm{R}=0.298$, $\mathrm{p}<0.01)$. Furthermore, corrected correlations between GPB with generativity $(0.436$, $\Delta \mathrm{R}=0.084), \mathrm{EC}(0.270, \Delta \mathrm{R}=0.044)$ and PSA $(0.436, \Delta \mathrm{R}=0.055)$ are also reported. These statistics endorsed the $\mathrm{H} 1$ because both real and observed statistics have positive relationships between GEN and GPB.

To test the mediation-based hypothesis, hierarchal regression was performed (see Table no. 3 for results). Moreover, the "squared population cross-validity coefficient" $\left(\mathrm{R}_{\mathrm{cv}}^{2}\right)$ was also performed for every model to manage the biasness linked 
with multiple-regression analysis, because they capitalize on chance and lead to change in $\mathrm{R}^{2}$ size when applied from one sample to another (Salgado et al., 2019). $\mathbf{R}_{\mathrm{cv}}^{2}$ is an effective estimate of effect size relative to other estimates resulted from regression analysis. To estimate the $\left(\mathrm{R}_{\mathrm{cv}}^{2}\right)$ we used Browne (1975) because the Monte Carlo analyses show greater efficacy relative to other formulae.

The results are as follows:

Table 3: Hierarchical Regression Analyses

\begin{tabular}{llll}
\hline & \multicolumn{3}{l}{ Dependent Variable } \\
\cline { 2 - 4 } Independent Variables & $\mathbf{E C}$ & $\mathbf{P S A}$ & $\mathbf{G P B}$ \\
\cline { 2 - 4 } & $\mathbf{B}$ & $\mathbf{B}$ & $\boldsymbol{\beta}$ \\
\hline Age & 0.029 & 0.026 & 0.029 \\
\hline Gender & $-0.222^{*}$ & -0.084 & 0.070 \\
\hline Program & 0.005 & 0.016 & 0.035 \\
\hline Generativity & $0.284^{* *}$ & $0.35^{* *}$ & $0.264^{* *}$ \\
\hline EC & & & $0.104^{*}$ \\
\hline PSB & & & $0.176^{* *}$ \\
\hline $\mathbf{R}^{2}$ & $0.100^{* *}$ & $0.13^{* *}$ & $0.176^{* *}$ \\
\hline $\mathbf{F}$ & 3.201 & 15.253 & 14.491 \\
\hline $\mathbf{R}$ & 0.317 & 0.360 & 0.419 \\
\hline $\mathbf{R}_{\text {cv }}^{2}$ & 0.094 & 0.124 & 0.167 \\
\hline
\end{tabular}

In the first step, EC was regressed with generativity and control variables. Generativity had a positive impact on EC $\left(\beta=0.284, p<0.01, R_{c v}^{2}=0.094\right)$. Similarly, in step 2 generativity and control variables were regressed with PSA. Generativity had a positive effect on PSA $\left(\beta=0.35, \mathrm{p}<0.01, \mathrm{R}_{\mathrm{cv}}^{2}=0.124\right)$. Lastly, generativity $(\beta=0.264, \mathrm{p}<0.01)$, mediators PSA $(\beta=0.176$, $\mathrm{p}<0.01)$, and EC $(\beta=0.104, \mathrm{p}<0.05)$ along with control variables are regressed with the dependent variable GPB. The $\mathrm{R}_{c \mathrm{cv}}^{2}$ calculated for this step was equal to 0.167. Grounded on the findings presented in Table no. 3, the mediating effects of EC and PSA were calculated, and the decision on hypotheses 2 and 3 was taken. The combined indirect effects of both the mediators are significant $(\beta=0.091, \mathrm{LLCI}=0.0499, \mathrm{ULCI}=0.1461)$. Hypothesis 2 is tested by assessing the individual indirect effect of EC. The results show that the indirect effect of EC is positive and significant with $\beta=0.0294$ (LLCI $=0.0025$, $\mathrm{ULCI}=0.0648$ ) proving ample proof for the approval of $\mathrm{H} 2$ that is an Environmental concern positively and significantly mediates the association between generativity and consumer green purchase behavior. Similarly, hypothesis 3 was also assessed by the results of indirect effects of PSA reported in Table 4. It is observed that the indirect effect of PSA is positive $(\beta=0.0616)$ and significant $(\mathrm{LLCI}=0.0275$, $\mathrm{ULCI}=0.1059)$ thus proving $\mathrm{H} 3$ that prosocial attitude significantly mediates the association between generativity and green purchase behavior.

Table 4: Indirect Effects of Generativity on Green Purchase Behavior

\begin{tabular}{lllll}
\hline & Effect & Boot SE & LLCI & ULCI \\
\hline TOTAL & 0.091 & 0.0242 & 0.0499 & 0.1461 \\
\hline EC & 0.0294 & 0.0152 & 0.0025 & 0.0648 \\
\hline PSA & 0.0616 & 0.0199 & 0.0275 & 0.1059
\end{tabular}

\section{DISCUSSION}

The present research contributes to the understanding of the antecedents of green purchase behavior. Green purchase behavior has become a core priority for both researchers and manufacturers of environmentally friendly goods and services. Although some factors (individual and organizational) have been found to affect green purchasing intentions and behaviors of people, examining generativity as an antecedent has been seldom researched. The findings of this study begin to make a connection between the present and the future in terms of environmental problems. This study adds new psychological factors to the model of environmentally friendly purchase behavior. This research offers several theoretical contributions. The present study contributes to the theory by providing additional insight into the factors that affect GPB, particularly the role of EC and prosocial attitude. Moreover, this study contributes by adding literature to the concept of generativity which has unexpectedly got limited attention in the literature of consumer behavior. This study expresses the concept of 
generativity in a novel way in the field of consumer green purchase behaviors. Theoretically, this research added to the literature of psychological attributes such as generativity and green purchase behaviors. This study contributed by bringing insight into understanding the impact of psychological influence on the adoption of green purchase behaviors. Even though the generative aspect of pro-environmental behavior has recently gained greater attention, much of the research tends to rely exclusively on individual predispositions. This article offers an insight into green behavior by focusing on how generative concern, environmental concern, and pro-social attitude derive environmentally friendly consumption. Empirical research that addresses the underlying mechanism that links generative concern with green purchase behaviors is very limited. The main contribution of our study is the examination of the process through which generative concern influences green purchase behavior.

Despite various studies in the past that worked on the factors affecting GPB, the gap between intention and actual purchase behavior is still not clear. Unlike previous researches, the present study examines the role of generative concern in the context of GPB. GPB is not a straightforward behavior and studies have identified that this complex phenomenon involves integrating various variables. The extent to which generativity could describe the variance in green consumption and green purchase behaviors is dependent on various intervening mechanisms. Among various factors that could intervene in the link between generativity and green purchasing, this study chooses EC and pro-social attitude as the mediating variables. The role of EC and prosocial attitude between the link of generativity and green purchase behaviors is novel and has not been examined previously. Empirical findings of this study revealed a positive and significant impact of generative concern on individual GPB. The empirical results of our study confirmed that those respondents who believe that their role for the future generation is valuable recorded greater intention to indulge in green purchase behaviors such as "buying organic, use energyefficient, or recycled products". The findings are consistent with previous studies (e.g, Shiel et al., 2020; Urien \& Kilbourne, 2011).

Moreover, our study also examines the mediating role of EC between the link of generativity and GPB. Results revealed that EC positively and significantly mediates the said association. The finding of this hypothesis is consistent with (Huang \& Liu, 2017; Zhang et al., 2015). However, the result contradicts the findings of (Malik et al., 2019). This study confirmed the positive and significant role of EC as a mediator between the link of GEN and EC. Those respondents who think that their contributions are important for future generations, demonstrate higher EC and engage in environmental behavior such as GPB.

Likewise, the mediating effect of pro-social attitude was examined between the link of generativity and green purchase behaviors. It is concluded that respondents who were high on generative concern reported a stronger prosocial attitude and express more involvement in green purchase behaviors. The result is consistent with previous researches that examined the role of prosocial attitude in green purchase behaviors (e.g, Busch \& Hofer, 2011; do Paco et al., 2019; Shiel et al., 2020).

\section{PRACTICAL IMPLICATIONS}

This study has some practical implications to offer. If an organization wants to manufacture green products/services, one of the most effective ways to market the products/services is to appeal to the audience that companies are doing to save future generations. For example, by constantly giving a message of valuing the future of your children and grandchildren in terms of a pollution-free planet and better living conditions, companies do attract consumers to buy their green products and services. Concern among people about the environment is also a factor that companies need to consider. Issues like global warming, adverse weather, climate change, unexpected calamities, floods, air pollution, increase in diseases, and water scarcity are some of the most important concerns for individuals. By focusing on these issues in advertising and marketing, the environmental concern of individuals can be increased.

\section{LIMITATIONS AND FUTURE RESEARCH}

There are some limitations of the current study. One of the main limitations of this study is that data were collected based on convenience sampling from a group of young adults. This may lead to the issue of generalizability and validity of results. For such an issue, we reported corrected correlations and squared population cross-validity coefficient $\mathrm{R}_{\mathrm{cv}}{ }_{\mathrm{c}}$ which shows what kind of results we could expect if similar relationships are studied in other samples. However, future studies must expand their sample and report results from a more diverse sample. Second, data were cross-sectional and future researchers may use experimental designs to observe the purchasing behaviors of individuals. Third, only two mediators were considered in this study. Green purchase behaviors are often complex and there could be a lot of other factors as well that could explain this process. For example, corporate social responsibility, green vision, green brand image, moral attentiveness, and price might be some of the factors that could result in interesting findings.

\section{ACKNOWLEDGEMENT}

We would like to thank all the independent reviewers of HSSR who conducted a feasibility study of our research work. 


\section{AUTHORS CONTRIBUTION}

All authors of this research paper have directly participated in the planning and execution of this study. Dr. Sajjad Ahmad Afridi and Dr. Maqsood Haider wrote the research paper and design the organization of this paper. Dr. Asad Shahjehan, Dr. Wajid Khan, and Miss Sajida Gul did the methodological part of this paper including; statistical analysis, interpretations, and technical parts.

\section{REFERENCES}

1. Abeliotis, K., Koniari, C., \& Sardianou, E. (2010). The profile of the green consumer in Greece. International journal of consumer studies, 34(2), 153-160. https://doi.org/10.1111/j.1470-6431.2009.00833.x

2. Achchuthan, S., \& Thirunavukkarasu, V. (2016). Enhancing purchase intentions towards sustainability: The influence of Environmental Attitude, Perceived Consumer effectiveness, health consciousness and social influence. Journal of Research for Consumers(30), 79-105.

3. Ahmad, W., Kim, W. G., Anwer, Z., \& Zhuang, W. (2020). Schwartz personal values, theory of planned behavior and environmental consciousness: How tourists' visiting intentions towards eco-friendly destinations are shaped? Journal of Business Research, 110, 228-236. https://doi.org/10.1016/j.jbusres.2020.01.040

4. Ajzen, \& Fishbein, M. (1980). Theory of Reasoned Action in understanding attitudes and predicting social behaviour. Englewood Cliffs, NJ: Prentice-Hall.

5. Alisat, S., Norris, J. E., Pratt, M. W., Matsuba, M. K., \& McAdams, D. P. (2014). Caring for the earth: Generativity as a mediator for the prediction of environmental narratives from identity among activists and nonactivists. Identity, 14(3), 177-194. https://doi.org/10.1080/15283488.2014.921172

6. Alwitt, L. F., \& Berger, I. E. (1993). Understanding the Link Between Environmental Attitudes and Consumer Product Usage: Measuring the Moderating Role of Attitude Strength. Advances in consumer research, 20(1), 189194.

7. Alwitt, L. F., \& Pitts, R. E. (1996). Predicting purchase intentions for an environmentally sensitive product. Journal of Consumer Psychology, 5(1), 49-64. https://doi.org/10.1207/s15327663jcp0501 03

8. Aubin, \& McAdams. (1995). The relations of generative concern and generative action to personality traits, satisfaction/happiness with life, and ego development. Journal of Adult Development, 2(2), 99-112. https://doi.org/10.1007/BF02251258

9. Aubin, McAdams, D. P., \& Kim, T.-C. E. (2004). The generative society: Caring for future generations. Washington, DC: American Psychological Association.

10. Bang, H. K., Ellinger, A. E., Hadjimarcou, J., \& Traichal, P. A. (2000). Consumer concern, knowledge, belief, and attitude toward renewable energy: An application of the reasoned action theory. Psychology \& Marketing, 17(6), 449-468. https://doi.org/10.1002/(SICI)1520-6793(200006)17:6<449::AID-MAR2>3.0.CO;2-8

11. Barnett, M. D., Archuleta, W. P., \& Cantu, C. (2019). Politics, concern for future generations, and the environment: Generativity mediates political conservatism and environmental attitudes. Journal of Applied Social Psychology, 49(10), 647-654. https://doi.org/10.1111/jasp.12624

12. Bertrandias, L., \& Elgaaied-Gambier, L. (2014). Others' environmental concern as a social determinant of green buying. Journal of consumer marketing, 31(6/7), 417-429. https://doi.org/10.1108/JCM-05-2014-0966

13. Biswas, A. (2017). A consumption value-gap analysis for sustainable consumption. Environmental Science and Pollution Research, 24(8), 7714-7725. https://doi.org/10.1007/s11356-016-8355-9

14. Bockman, S., Razzouk, N. Y., \& Sirotnik, B. (2009). Going green-from left to center stage: An empirical perspective. Journal of American Academy of Business, 14(2), 8-17.

15. Bray, J., Johns, N., \& Kilburn, D. (2011). An exploratory study into the factors impeding ethical consumption. Journal of Business Ethics, 98(4), 597-608. https://doi.org/10.1007/s10551-010-0640-9

16. Browne, M. (1975). Predictive validity of a linear regression equation. British Journal of Mathematical and Statistical Psychology, 28(1), 79-87. https://doi.org/10.1111/j.2044-8317.1975.tb00550.x

17. Buerke, A., Straatmann, T., Lin-Hi, N., \& Müller, K. (2017). Consumer awareness and sustainability-focused value orientation as motivating factors of responsible consumer behavior. Review of Managerial Science, 11(4), 959-991. https://doi.org/10.1007/s11846-016-0211-2

18. Busch, H., \& Hofer, J. (2011). Identity, prosocial behavior, and generative concern in German and Cameroonian Nso adolescents. Journal of Adolescence, 34(4), 629-638. https://doi.org/10.1016/j.adolescence.2010.09.009

19. Carrus, G., Bonaiuto, M., \& Bonnes, M. (2005). Environmental concern, regional identity, and support for protected areas in Italy. Environment and Behavior, 37(2), 237-257. https://doi.org/10.1177/0013916504269644

20. Cerri, J., Testa, F., \& Rizzi, F. (2018). The more I care, the less I will listen to you: How information, environmental concern and ethical production influence consumers' attitudes and the purchasing of sustainable products. Journal of Cleaner Production, 175, 343-353. https://doi.org/10.1016/j.jclepro.2017.12.054 
21. Chan, T. S. (2009). Environmental sustainability as a generative concern: An exploratory study of the narrative identities of leaders in the environmental sustainability movement. (3386903 Ph.D.), Northwestern University, Ann Arbor. Retrieved from https://search.proquest.com/dissertations-theses/environmental-sustainability-asgenerative/d ocview/304970123/se-2?accountid=135034

22. Chaudhary, R., \& Bisai, S. (2018). Factors influencing green purchase behavior of millennials in India. Management of Environmental Quality: An International Journal, 29(5), 798-812. https://doi.org/10.1108/MEQ02-2018-0023

23. Chen, \& Chai, L. T. (2010). Attitude towards the environment and green products: Consumers' perspective. Management science and engineering, 4(2), 27-39.

24. Chen, \& Chang, C.-H. (2013). Greenwash and green trust: The mediation effects of green consumer confusion and green perceived risk. Journal of Business Ethics, 114(3), 489-500. https://doi.org/10.1007/s10551-012-1360-0

25. Cleveland, M., Kalamas, M., \& Laroche, M. (2012). "It's not easy being green": Exploring green creeds, green deeds, and internal environmental locus of control. Psychology \& Marketing, 29(5), 293-305. https://doi.org/10.1002/mar.20522

26. Cole, E. R., \& Stewart, A. J. (1996). Meanings of political participation among Black and White women: Political identity and social responsibility. Journal of Personality and Social Psychology, 71(1), 130. https://doi.org/10.1037/0022-3514.71.1.130

27. de Espanés, G. M., Villar, F., Urrutia, A., \& Serrat, R. (2015). Motivation and commitment to volunteering in a sample of Argentinian adults: what is the role of generativity? Educational Gerontology, 41(2), 149-161. https://doi.org/10.1080/03601277.2014.946299

28. Dietz, T., Stern, P. C., \& Guagnano, G. A. (1998). Social structural and social psychological bases of environmental concern. Environment and Behavior, 30(4), 450-471. https://doi.org/10.1177/001 391659803000402

29. do Paco, A., Shiel, C., \& Alves, H. (2019). A new model for testing green consumer behaviour. Journal of Cleaner Production, 207, 998-1006. https://doi.org/10.1016/j.jclepro.2018.10.105

30. Dunlap, R. E., \& Jones, R. E. (2002). Environmental concern: Conceptual and measurement issues. Handbook of environmental sociology, 3(6), 482-524.

31. Dunlap, R. E., Van Liere, K. D., Mertig, A. G., \& Jones, R. E. (2000). New trends in measuring environmental attitudes: measuring endorsement of the new ecological paradigm: a revised NEP scale. Journal of Social Issues, 56(3), 425-442. https://doi.org/10.1111/0022-4537.00176

32. Erikson, E. H. (1950). Growth and crises of the "healthy personality." Symposium on the healthy personality. (pp. 91-146). Oxford, England: Josiah Macy, Jr. Foundation.

33. Farrow, K., Grolleau, G., \& Ibanez, L. (2017). Social norms and pro-environmental behavior: A review of the evidence. Ecological Economics, 140, 1-13. https://doi.org/10.1016/j.ecolecon.2017.04.017

34. Fransson, N., \& Gärling, T. (1999). Environmental concern: Conceptual definitions, measurement methods, and research findings. Journal of Environmental Psychology, 19(4), 369-382. https://doi.org/10.1006/jevp.1999.0141

35. Gifford, R. (2008). Psychology's essential role in alleviating the impacts of climate change. Canadian Psychology/psychologie canadienne, 49(4), 273. https://doi.org/10.1037/a0013234

36. Groening, C., Sarkis, J., \& Zhu, Q. (2018). Green marketing consumer-level theory review: A compendium of applied theories and further research directions. Journal of Cleaner Production, 172, 1848-1866. https://doi.org/10 .1016/j.jclepro.2017.12.002

37. Grunert, K. G. (1995). Development and testing of a cross-culturally valid instrument: food-related life style. ACR North American Advances, 22, 475-480.

38. Guiney, M. S., \& Oberhauser, K. S. (2009). Conservation volunteers' connection to nature. Ecopsychology, l(4), 187-197. https://doi.org/10.1089/eco.2009.0030

39. Gupta, S., \& Ogden, D. T. (2009). To buy or not to buy? A social dilemma perspective on green buying. Journal of consumer marketing, 26(6), 376-391. https://doi.org/10.1108/07363760910988201

40. Han, H. (2020). Theory of green purchase behavior (TGPB): A new theory for sustainable consumption of green hotel and green restaurant products. Business Strategy and the Environment, 29(6), 2815-2828. https://doi.org/ $\underline{10.1002 / \mathrm{bse} .2545}$

41. Han, H., Hwang, J., \& Lee, M. J. (2017). The value-belief-emotion-norm model: Investigating customers' ecofriendly behavior. Journal of Travel \& Tourism Marketing, 34(5), 590-607. https://doi.org/10.1080/105 48408.2016.1208790

42. Hansmann, R., Laurenti, R., Mehdi, T., \& Binder, C. R. (2020). Determinants of pro-environmental behavior: A comparison of university students and staff from diverse faculties at a Swiss University. Journal of Cleaner Production, 268, 121864. https://doi.org/10.1016/j.jclepro.2020.121864 
43. Hart, H. M., McAdams, D. P., Hirsch, B. J., \& Bauer, J. J. (2001). Generativity and social involvement among African Americans and White adults. Journal of research in personality, 35(2), 208-230. https://doi.org/10. 1006/jrpe.2001.2318

44. Hartmann, P., \& Apaolaza-Ibáñez, V. (2012). Consumer attitude and purchase intention toward green energy brands: The roles of psychological benefits and environmental concern. Journal of Business Research, 65(9), 1254-1263. https://doi.org/10.1016/j.jbusres.2011.11.001

45. He, A. z., Cai, T., Deng, T. x., \& Li, X. (2016). Factors affecting non-green consumer behaviour: an exploratory study among $\mathrm{C}$ hinese consumers. International journal of consumer studies, 40(3), 345-356. https://doi.org/10.11 $11 / \mathrm{ijcs} .12261$

46. Heo, J., \& Muralidharan, S. (2019). What triggers young Millennials to purchase eco-friendly products?: the interrelationships among knowledge, perceived consumer effectiveness, and environmental concern. Journal of Marketing Communications, 25(4), 421-437. https://doi.org/10.1080/13527266.2017.1303623

47. Horwitz, W. A. (1996). Developmental origins of environmental ethics: The life experiences of activists. Ethics \& Behavior, 6(1), 29-53. https://doi.org/10.1207/s15327019eb0601_3

48. Hsu, P.-C. (2016). Global monsoon in a changing climate The Monsoons and Climate Change (pp. 7-24). Cham: Springer. https://doi.org/10.1007/978-3-319-21650-8_2

49. Huang, Y.-C., \& Liu, C.-H. S. (2017). Moderating and mediating roles of environmental concern and ecotourism experience for revisit intention. International Journal of Contemporary Hospitality Management, 29(7), 18541872. https://doi.org/10.1108/IJCHM-12-2015-0677

50. Ifegbesan, A. P., \& Rampedi, I. T. (2018). Understanding the role of socio-demographic and geographical location on pro-environmental behavior in Nigeria. Applied Environmental Education \& Communication, 17(4), 335-351. https://doi.org/10.1080/1533015X.2017.1419102

51. IPCC, C. C. (2014). Mitigation of climate change (B. Metz, O. Davidson, P. Bosch \& R. Dave Eds.). Geneva Cambridge Univ. Press.

52. Jaiswal, D., \& Kant, R. (2018). Green purchasing behaviour: A conceptual framework and empirical investigation of Indian consumers. Journal of Retailing and consumer services, 41, 60-69. https://doi.org/10.101 6/j.jretconser.2017.11.008

53. Johnson, C. Y., Bowker, J. M., \& Cordell, H. K. (2004). Ethnic variation in environmental belief and behavior: An examination of the new ecological paradigm in a social psychological context. Environment and Behavior, 36(2), 157-186. https://doi.org/10.1177/0013916503251478

54. Joshi, Y., \& Rahman, Z. (2015). Factors affecting green purchase behaviour and future research directions. International Strategic management review, 3(1-2), 128-143. https://doi.org/10.1016/j.ism.2015.04.001

55. Kalafatis, S. P., Pollard, M., East, R., \& Tsogas, M. H. (1999). Green marketing and Ajzen's theory of planned behaviour: a cross-market examination. Journal of consumer marketing, 16(5), 441-460. https://doi.org/10. $1108 / 07363769910289550$

56. Keho, Y. (2016). What drives energy consumption in developing countries? The experience of selected African countries. Energy Policy, 91, 233-246. https://doi.org/10.1016/j.enpol.2016.01.010

57. Kim, Y., \& Choi, S. M. (2005). Antecedents of green purchase behavior: An examination of collectivism, environmental concern, and PCE. ACR North American Advances, 32, 592-599.

58. Kotre, J. N. (1984). Outliving the self: Generativity and the interpretation of lives: Johns Hopkins University Press.

59. Kropfeld, M. I., Nepomuceno, M. V., \& Dantas, D. C. (2018). The ecological impact of anticonsumption lifestyles and environmental concern. Journal of Public Policy \& Marketing, 37(2), 245-259. https://doi.org/10.1177 /0743915618810448

60. Kulin, J., \& Johansson Sevä, I. (2020). Quality of government and the relationship between environmental concern and pro-environmental behavior: a cross-national study. Environmental Politics, 1-26. https://doi.org/10.1 080/09644016.2020.1809160

61. Lacroix, C., \& Jolibert, A. (2015). Targeting consumers who care about future generations. Psychology \& Marketing, 32(8), 783-794. https://doi.org/10.1002/mar.20818

62. Liobikienè, G., \& Bernatonienè, J. (2017). Why determinants of green purchase cannot be treated equally? The case of green cosmetics: Literature review. Journal of Cleaner Production, 162, 109-120. https://doi.org/10.10 16/j.jclepro.2017.05.204

63. Malik, M. I., Mir, F. N., Hussain, S., Hyder, S., Anwar, A., Khan, Z. U., . . Waseem, M. (2019). Contradictory results on environmental concern while re-visiting green purchase awareness and behavior. Asia Pacific Journal of Innovation and Entrepreneurship, 13(1), 17-28. https://doi.org/10.1108/APJIE-11-2018-0061

64. Marcia, J. E. (2010). Life transitions and stress in the context of psychosocial development Handbook of stressful transitions across the lifespan (pp. 19-34): Springer. https://doi.org/10.1007/978-1-4419-0748-6_2 
65. McAdams, D. P., \& Aubin, E. (1992). A theory of generativity and its assessment through self-report, behavioral acts, and narrative themes in autobiography. Journal of Personality and Social Psychology, 62(6), 1003. https://doi.org/10.1037/0022-3514.62.6.1003

66. Milfont, T. L., \& Sibley, C. G. (2011). Exploring the concept of environmental generativity. International Journal of Hispanic Psychology, 4(1), 21.

67. Moisander, J. (2007). Motivational complexity of green consumerism. International journal of consumer studies, 31(4), 404-409. https://doi.org/10.1111/j.1470-6431.2007.00586.x

68. Moore, K. D., \& Nelson, M. P. (2010). Toward a global consensus for ethical action. Moral Ground: Ethical Action for a Planet in Peril. Trinity University Press, San Antonio.

69. Morselli, D., \& Passini, S. (2015). Measuring prosocial attitudes for future generations: The social generativity scale. Journal of Adult Development, 22(3), 173-182. https://doi.org/10.1007/s10804-015-9210-9

70. Osgood, J. M., \& Muraven, M. (2015). Self-control depletion does not diminish attitudes about being prosocial but does diminish prosocial behaviors. Basic and Applied Social Psychology, 37(1), 68-80. https://doi.org/10.1 080/01973533.2014.996225

71. Paço, A., Alves, H., Shiel, C., \& Filho, W. L. (2013). Development of a green consumer behaviour model. International journal of consumer studies, 37(4), 414-421. https://doi.org/10.1111/ijcs.12009

72. Paul, J., Modi, A., \& Patel, J. (2016). Predicting green product consumption using theory of planned behavior and reasoned action. Journal of Retailing and consumer services, 29, 123-134. https://doi.org/10.1016/j.jret conser.2015.11.006

73. Peterson, B. E., Smirles, K. A., \& Wentworth, P. A. (1997). Generativity and authoritarianism: Implications for personality, political involvement, and parenting. Journal of Personality and Social Psychology, 72(5), 1202. https://doi.org/10.1037/0022-3514.72.5.1202

74. Peterson, B. E., \& Stewart, A. J. (1993). Generativity and social motives in young adults. Journal of Personality and Social Psychology, 65(1), 186. https://doi.org/10.1037/0022-3514.65.1.186

75. Peterson, B. E., \& Stewart, A. J. (1996). Antecedents and contexts of generativity motivation at midlife. Psychology and Aging, 11(1), 21. https://doi.org/10.1037/0882-7974.11.1.21

76. Polonsky, M. J., Vocino, A., Grimmer, M., \& Miles, M. P. (2014). The interrelationship between temporal and environmental orientation and pro-environmental consumer behaviour. International journal of consumer studies, 38(6), 612-619. https://doi.org/10.1111/ijcs.12131

77. Pothitou, M., Hanna, R. F., \& Chalvatzis, K. J. (2016). Environmental knowledge, pro-environmental behaviour and energy savings in households: An empirical study. Applied Energy, 184, 1217-1229. https://doi.org/10.1016 /j.apenergy.2016.06.017

78. Prakash, G., Choudhary, S., Kumar, A., Garza-Reyes, J. A., Khan, S. A. R., \& Panda, T. K. (2019). Do altruistic and egoistic values influence consumers' attitudes and purchase intentions towards eco-friendly packaged products? An empirical investigation. Journal of Retailing and consumer services, 50, 163-169. https://doi.org/10.1016/j.jretconser.2019.05.011

79. Pratt, M. W., Norris, J. E., Alisat, S., \& Bisson, E. (2013). Earth mothers (and fathers): Examining generativity and environmental concerns in adolescents and their parents. Journal of moral education, 42(1), 12-27. https://doi.org/10.1080/03057240.2012.714751

80. Ramayah, T., \& Rahbar, E. (2013). Greening the environment through recycling: an empirical study. Management of Environmental Quality: An International Journal, 24(6), 782-801. https://doi.org/10.1108/MEQ-07-2012-0054

81. Salgado, J. F., Blanco, S., \& Moscoso, S. (2019). Subjective well-being and job performance: Testing of a suppressor effect. Journal of Work and Organizational Psychology, 35(2), 93-102. https://doi.org/10.5093/jwop2019a9

82. Schmidt, F. L. (2015). History and development of the Schmidt-Hunter meta-analysis methods. Research synthesis methods, 6(3), 232-239. https://doi.org/10.1002/jrsm.1134

83. Schultz, P. W. (2001). The structure of environmental concern: Concern for self, other people, and the biosphere. Journal of Environmental Psychology, 21(4), 327-339. https://doi.org/10.1006/jevp.2001.0227

84. Serrat, R., Villar, F., Warburton, J., \& Petriwskyj, A. (2017). Generativity and political participation in old age: A mixed-method study of Spanish elders involved in political organisations. Journal of Adult Development, 24(3), 163-176. https://doi.org/10.1007/s10804-016-9255-4

85. Shiel, C., do Paco, A., \& Alves, H. (2020). Generativity, sustainable development and green consumer behaviour. Journal of Cleaner Production, 245, 118865. https://doi.org/10.1016/j.jclepro.2019.118865

86. Son, J., \& Wilson, J. (2011). Generativity and volunteering. Paper presented at the Sociological Forum. https://doi.org/10.1111/j.1573-7861.2011.01266.x 
87. Song, Y., Qin, Z., \& Yuan, Q. (2019). The impact of eco-label on the young Chinese generation: The mediation role of environmental awareness and product attributes in green purchase. Sustainability, 11(4), 973. https://doi.org/10.3390/su11040973

88. Sreen, N., Purbey, S., \& Sadarangani, P. (2018). Impact of culture, behavior and gender on green purchase intention. Journal of Retailing and consumer services, 41, 177-189. https://doi.org/10.1016/j.jretc onser.2017.12.002

89. Steele, W. R., Schreiber, G. B., Guiltinan, A., Nass, C., Glynn, S. A., Wright, D. J., . . Smith, J. W. (2008). The role of altruistic behavior, empathetic concern, and social responsibility motivation in blood donation behavior. Transfusion, 48(1), 43-54.

90. Steg, L., \& Vlek, C. (2009). Encouraging pro-environmental behaviour: An integrative review and research agenda. Journal of Environmental Psychology, 29(3), 309-317. https://doi.org/10.1016/j.jenvp.2008.10.004

91. Testa, F., Iraldo, F., Vaccari, A., \& Ferrari, E. (2015). Why eco-labels can be effective marketing tools: Evidence from a study on Italian consumers. Business Strategy and the Environment, 24(4), 252-265. https://doi.org/ $10.1002 / \mathrm{bse} .1821$

92. Thielmann, I., Spadaro, G., \& Balliet, D. (2020). Personality and prosocial behavior: A theoretical framework and meta-analysis. Psychological bulletin, 146(1), 30. https://doi.org/10.1037/bul0000217

93. Timilsina, R. R., Kotani, K., \& Kamijo, Y. (2019). Generativity and social value orientation between rural and urban societies in a developing country. Futures, 105, 124-132. https://doi.org/10.1016/j.futures.2018.09.003

94. Urien, B., \& Kilbourne, W. (2008). Generativity and its relationship to eco-friendly behavioral intentions and environmentally responsible consumption behavior. Paper presented at the THE $33 \mathrm{rd}$ ANNUAL MEETING OF THE MACROMARKETING SOCIETY 2008.

95. Urien, B., \& Kilbourne, W. (2011). Generativity and self-enhancement values in eco-friendly behavioral intentions and environmentally responsible consumption behavior. Psychology \& Marketing, 28(1), 69-90. https://doi.org/10.1002/mar.20381

96. Vicente-Molina, M., Fernández-Sainz, A., \& Izagirre-Olaizola, J. (2018). Does gender make a difference in proenvironmental behavior? The case of the Basque Country University students. Journal of Cleaner Production, 176, 89-98. https://doi.org/10.1016/j.jclepro.2017.12.079

97. Wang, L., Wong, P. P. W., \& Alagas, E. N. (2020). Antecedents of green purchase behaviour: an examination of altruism and environmental knowledge. International Journal of Culture, Tourism and Hospitality Research, 14(1), 63-82. https://doi.org/10.1108/IJCTHR-02-2019-0034

98. Water, D. A., \& McAdams, D. P. (1989). Generativity and Erikson's "belief in the species". Journal of research in personality, 23(4), 435-449. https://doi.org/10.1016/0092-6566(89)90013-5

99. Weigel, R. H. (1983). Environmental attitudes and the prediction of behavior. Environmental psychology: Directions and perspectives, 257-287.

100. Weinstein, N., \& Ryan, R. M. (2010). When helping helps: autonomous motivation for prosocial behavior and its influence on well-being for the helper and recipient. Journal of Personality and Social Psychology, 98(2), 222. https://doi.org/10.1037/a0016984

101. Welte, T. H., \& Anastasio, P. A. (2010). To conserve or not to conserve: is status the question? Environment and Behavior, 42(6), 845-863. https://doi.org/10.1177/0013916509348461

102. Witek, L., \& Kuźniar, W. (2021). Green Purchase Behavior: The Effectiveness of Sociodemographic Variables for Explaining Green Purchases in Emerging Market. Sustainability, 13(1), 209. https://doi.org/10.3390/su13010209

103. Wu, J., Liao, H., Wang, J.-W., \& Chen, T. (2019). The role of environmental concern in the public acceptance of autonomous electric vehicles: A survey from China. Transportation Research Part F: Traffic Psychology and Behaviour, 60, 37-46. https://doi.org/10.1016/j.trf.2018.09.029

104. Yew, P.-N., Lim, Y.-Y., \& Lee, W.-L. (2019). Tannic acid-rich porcupine bezoars induce apoptosis and cell cycle arrest in human colon cancer cells. Pharmacognosy Magazine, 15(65), 523. https://doi.org/10 .4103/pm.pm_620_18

105. Zabkar, V., \& Hosta, M. (2013). Willingness to act and environmentally conscious consumer behaviour: can prosocial status perceptions help overcome the gap? International journal of consumer studies, 37(3), 257-264. https://doi.org/10.1111/j.1470-6431.2012.01134.X

106. Zhang, B., Wang, Z., \& Lai, K.-h. (2015). Mediating effect of managers' environmental concern: Bridge between external pressures and firms' practices of energy conservation in China. Journal of Environmental Psychology, 43, 203-215. https://doi.org/10.1016/j.jenvp.2015.07.002

107. Zhao, H.-h., Gao, Q., Wu, Y.-p., Wang, Y., \& Zhu, X.-d. (2014). What affects green consumer behavior in China? A case study from Qingdao. Journal of Cleaner Production, 63, 143-151. https://doi.org/10.101 6/j.jclepro.2013.05.021 